\title{
"The Next Generation of International Law: Space, Ice, and the Cosmolegal Proposal"
}

\section{Cirkovic, Elena}

2021-03

Cirkovic , E 2021 , ' "The Next Generation of International Law: Space, Ice, and the Cosmolegal Proposal" ' , German law journal , vol. 22 , no. 2 , 2071832221000043 , pp. pÿ147 167 . https://doi.org/10.1017/glj.2021.4

http://hdl.handle.net/10138/329188

https://doi.org/10.1017/glj.2021.4

cc_by

publishedVersion

Downloaded from Helda, University of Helsinki institutional repository.

This is an electronic reprint of the original article.

This reprint may differ from the original in pagination and typographic detail.

Please cite the original version. 


\title{
The Next Generation of International Law: Space, Ice, and the Cosmolegal Proposal
}

\section{Elena Cirkovic*}

Aleksanteri Institute-Finnish Centre for Russian and East European Studies, Helsinki Institute of Sustainability Science (HELSUS), University of Helsinki, Helsinki, Finland

Corresponding author: Elena Cirkovic, Email: elena.cirkovic@helsinki.fi

(Received 21 June 2020; accepted 21 September 2020)

\begin{abstract}
With the increasing environmental degradation in spaces most affected by climate change such as the Arctic, and the extension of anthropogenic environmental problems even into the Earth's orbit, international law is confronted with some unprecedented challenges. Much of the legal dialogue surrounding this question is taking place in the abstract, such that there are no exact proposals for methodological and practical applications in lawmaking. In this Article, I argue that current governance relevant to the Arctic and outer space precedes an understanding of these spaces. Critical posthumanism, and other approaches, point out the continuation of strict boundaries that have been set up between the human body and the environment. International law's formalist doctrinal deductions exacerbate these boundaries. I propose an approach to lawmaking under a broad term: the cosmolegal. The cosmolegal proposal challenges distinctions between human-made and non-human "laws" - scientific and social laws - and questions the foundational determination of both. The framework I suggest in this Article, therefore, requires a new approximation to accuracy in lawmaking, which could be achieved by greater interdisciplinarity and acceptance of ontological pluralism. This Article is divided into two broader sections. The first section focuses on two environmental problems: A) greenhouse gas (GHG) emissions in the Arctic and B) orbital debris. The second section argues for a different ontology of law and human self-understanding in the context of the unknown. It proposes "cosmolegality" in an attempt to approximate the inclusion and representation of 'everything considered to be non-human.
\end{abstract}

Keywords: The cosmolegal; Arctic law; orbital debris; climate change; posthumanism; Earth system

"Into this wild Abyss/The womb of Nature, and perhaps her grave-/Of neither sea, nor shore, nor air, nor fire,/But all these in their pregnant causes mixed/Confusedly, and which thus must ever fight”

${ }^{\star}$ Dr. Elena Cirkovic is a researcher at the Aleksanteri Institute-Finnish Centre for Russian and East European Studies and the Helsinki Institute of Sustainability Science.

Research for this article was funded by a grant from the National Research University Higher School of Economics, St. Petersburg, Grant № 18 - IP - 01, Russian Federation, and the Kone Foundation Fellowship at the Helsinki Institute for Advanced Studies (HCAS), Finland.

I wish to thank the following colleagues for their extensive comments, support, and reviews: Steven Freeland, Ram Jakhu, Isabel Feichtner, Nikolas Rajkovic, Pierre Cloutier de Repentigny, Moriba Jah, Danielle Wood, Christiane Wilke, and Jan Klabbers. All omissions and mistakes are my own. Also, many thanks to Martti Koskenniemi and the Erik Castrén Institute (ECI), Helsinki University, for providing a space and place for this research project. 


\section{A. Introduction}

The Arctic is one of the fastest warming places on the planet. As temperatures rise, the frozen layer of soil, called permafrost, begins to thaw, releasing methane $\left(\mathrm{CH}_{4}\right)$ and other greenhouse gases (GHGs) into the atmosphere. These emissions accelerate future warming, and the extent of these effects requires ongoing measurements of the emissions and related environmental factors. ${ }^{1}$

In July 2020, an explosion in the Yamal Peninsula above the Arctic Circle caused by subterranean gases opened up a massive hole. Russian scientists found the 50-meter crater on an expedition. ${ }^{2}$ They named it Crater 17, as 16 similar objects have been discovered in Siberia's extreme northwest since the phenomenon was first observed in $2014 .{ }^{3}$ Yevgeny Chuvilin, a Moscow-based geologist with the Skolkovo Institute of Science and Technology, told the New York Times that "[i] $\mathrm{t}$ was making noises. It was like something alive."” The inaccessibility of the Arctic region has limited various types of ground-based observations to places with existing infrastructure, which can delay understanding of phenomena such as the methane craters. This is where outer space technology has been crucial. Satellite observation has been one of the ways to monitor such phenomena. ${ }^{5}$ Ability to identify the likely causes of the distribution of $\mathrm{CH}_{4}$ hotspots, for example, is needed for better accuracy in the monitoring of GHGs emissions and forecasting of global climate change impacts on the Arctic. ${ }^{6}$

The case Arctic $\mathrm{CH}_{4}$ release demonstrates how various disciplines span across different domains in order to address climate change on Earth. This Article identifies two planetary environmental challenges: (1) the effects of greenhouse gas (GHG) emissions in the Arctic; and (2) orbital debris, or human-made objects polluting the Earth's orbit. ${ }^{7}$ Orbital debris poses a risk to functional space objects in orbit. It hinders observation of the complex variables involved in climate change, such as the melting permafrost and ice in the Arctic. International law lags behind these developments and lacks effective regimes for the regulation of climate change or orbital debris mitigation.

New forms of access to remote areas of the Earth and outer space are increasingly facilitated by technological and scientific advances now combined with growing privatization. This includes the

\footnotetext{
${ }^{1}$ Dmitry Yumashev et al., Climate Policy Implications of Nonlinear Decline of Arctic Land Permafrost and Other Cryosphere Elements, 10 NATURE COMmunications 1 (2019).

${ }^{2}$ The local news provided images of the crater. See Вести Ямал, Сенсационная находка: на Ямале вновь обнаружили огромную воронку (“Sensational Find: A Huge Crater Was Again Discovered in Yamal”), YouTuBE (Aug. 28, 2020), https:// www.youtube.com/watch?time_continue $=1 \& \mathrm{v}=\mathrm{q} 3 \mathrm{fQ}$ ok8iQ94\&feature $=$ emb_title.

${ }^{3}$ In 1978, NASA scientists Donald Kessler and Burton Cour-Palais first described the problem of multiplying orbital space debris in their article Collision Frequency of Artificial Satellites: The Creation of a Debris Belt. See Donald Kessler \& Burton Cour-Palais, Collision Frequency of Artificial Satellites: The Creation of a Debris Belt, 83 SPACE PHYsICS 2637 (1978). The multiplying debris became known as the "Kessler Syndrome," and instead of an image of a limitless environment, it became clear that the orbital space was a very fragile area. Orbital debris is one of the main challenges resulting from anthropocentric outer space use.

${ }^{4}$ Andrew Kramer, Land in Russia's Arctic Blows 'Like a Bottle of Champagne', N.Y. Times (Sept. 5, 2020), https://www. nytimes.com/2020/09/05/world/europe/russia-arctic-eruptions.html\#: :text=Since\%20finding\%20the\%20first $\% 20 \mathrm{crater}$,gas \%20trapped\%20in\%20thawing\%20permafrost.

${ }^{5}$ David R. Thompson, Clayton D. Elder, Andrew K. Thorpe, Philip Hanke, Katey M. Walter Anthony, \& Charles E. Miller Airborne Mapping Reveals Emergent Power Law of Arctic Methane Emissions, 47 GeOpHysiCal RsCH. LetTERS 3 (2020).

${ }^{6}$ Intergovernmental Panel on Climate Change, Global Warming of $1.5^{\circ} \mathrm{C}$ : An IPCC Special Report on the Impacts of Global Warming of $1.5^{\circ} \mathrm{C}$ Above Pre-Industrial Levels and Related Global Greenhouse Gas Emission Pathways, in the Context of Strengthening the Global Response to the Threat of Climate Change, Sustainable Development, and Efforts to Eradicate Poverty (2019). See also The Norwegian Barents Secretariat, Resilience Related to Sustainable Development in Globalization 17 (2016), https://calotte-academy. com/sites/default/files/2017-08/CA-2016-Final_Report.pdf.

${ }^{7}$ Christine Joseph \& Danielle Wood, Analysis of the Microgravity Research Ecosystem and Market Drivers of Accessibility, 70TH INT'L Astronautical Cong. 2019 (Oct. 25, 2019) (abstract available at https://iafastro.directory/iac/paper/id/50549/ abstract-pdf/IAC-19,A2,6,5,x50549.brief.pdf?2019-03-28.10:00:14).
} 
many firms launching mega-constellations and planning future microgravity platforms. ${ }^{8}$ Space technology also delivers data crucial for monitoring climate change in remote regions of the Earth such as the Arctic. The theoretical premise of this Article is that the non-human phenomena, like GHGs and orbital debris, are unpredictable and disruptive agents. They are unintended results of human activities and, in turn, have the capacity to affect all planetary life, both human and non-human.

This Article proposes a concept to encompass the process of learning and lawmaking through which the law would recognize the unpredictability of human and non-human relations, or the cosmolegal. It responds to the need for a new ontological understanding of the global politicojuridical space. What are the implications of recognizing that everything-including rocks, polluted air, the oceans-is alive? Cosmolegality emerges from theories on posthuman legalities that argue for a move beyond the centrality, for law, of the human subject that acts upon the world, the cosmos, as its object. Instead of giving the complete picture of world dynamics, cosmolegality would have to leave a free parameter or some disjunction for future contingencies and uncertainties on Earth and in outer space. The main hypothesis of this Article is that the international legal response to climate change on Earth, atmospheric pollution, and pollution caused by human activities in orbital space requires a new ontological approach to the law itself. Beyond its scope, however, is the discussion of the internal human split of its biological and subjective agency, and by default, the capacity to any complete understanding of consequences of human activities, including scientific and technological advances.

The "resource rush" in the Arctic and outer space reveals the short-sightedness of attempts to instrumentalize and colonize these spaces while sidestepping environmental problems. The new space race has already resulted in a saturation of orbital carrying capacity. The Arctic and outer space are both subject to the current state-extractive industry promotion of resource extraction. They are governed by international regimes that do not directly respond to the magnitude of the ongoing environmental degradation. The orbital space also has capacity limits, which are not only determined by the number of anthropogenic space objects in a specific orbital neighborhood, but also the uncertainty in how these objects will behave in the future. ${ }^{9}$

The dominant debates in international law, as related to ongoing and future human activities in outer space, have focused recently on the military and commercial uses of outer space, with international lawyers participating in the delineation of what the public-private, state-commerce nexus of relations should become. ${ }^{10}$ SpaceX launches continue to pose some questions regarding their impact on the environment. ${ }^{11}$ NASA and its international partners have advanced bilateral cooperation with first signings of The Artemis Accords Principles for Cooperation in the Civil Exploration and Use of the Moon, Mars, Comets, and Asteroids for Peaceful Purposes. ${ }^{12}$ However, the space environment question requires a consideration of its existence beyond potential utility for the human species.

What evades human-made law is that much of the Earth system, the orbit, or the extraterrestrial space beyond Earth's orbit, are operating under the laws of physics, chemistry, biology, and so on. This includes human bodies. Viruses, gases, or rocks do not in any way, shape, or form, bend themselves to public policy. While this has become evident in the current pandemic, it has been a

\footnotetext{
${ }^{8}$ For a discussion in the context of the Starlink mega constellation, see Jonathan McDowell, The Low Earth Orbit Satellite Population and Impact of the Space X Starlink Constellation, 892 APJL 1 (2020), https://arxiv.org/abs/2003.07446.

${ }^{9}$ For ongoing observations of "space junk" behavior, see Jonathan McDowell, GCAT: General Catalog of Artificial Space Objects, PlANET 4589 (Dec. 29, 2020), https://planet4589.org/space/gcat/web/cat/index.html.

${ }^{10}$ Building Blocks for the Development of an International Framework for the Governance of Space Resource Activities: A Commentary (Olavo O. Bittencourt Neto et al. eds., 2020).

${ }^{11}$ See McDowell, supra note 8.

${ }^{12}$ The Artemis Accords: Principles for Cooperation in the Civil Exploration and Use of the Moon, Mars, Comets, and Asteroids for Peaceful Purposes, Oct. 13, 2020, https://www.nasa.gov/specials/-accords/img/Artemis-Accords-signed13Oct2020.pdf [hereinafter Artemis Accords].
} 
long-term issue for humanity's mainstream legal theory, study, and practice. The current legal systems addressing climate change and outer space are not driven by the realities of their environments, but by the formalistic and anthropocentric structure of international law. There is much discussion on international environmental law, climate regime, and at the moment, outer space law, which is again on the agenda in interstate relations. There is, as of yet, no encompassing "bird's-eye" normative view that addresses the core problem of international legal form and practice.

The cosmolegal proposal builds on the hypothesis of profound interrelatedness in the Earth system. ${ }^{13}$ Earth System Science (ESS) is the application of systems science to Earth sciences and approaches the Earth as a self-enclosed system, which includes interacting physical, chemical, and biological processes. The Earth system approach also allows us to understand the Earth on a planetary scale. ${ }^{14}$ Human-caused environmental problems are not only contained on Earth. Accordingly, we need to recognize, evaluate, and address connections intertwined in human activities on Earth, as well as human excursions into the environment beyond the uppermost layers of atmosphere, in the Earth's orbit, and into the more "cosmic" realm.

The applied definitions in this Article are as follows. Outer space refers to the region beyond the earth's atmosphere that begins at an altitude of 100 kilometers above Earth's sea level. ${ }^{15}$ An orbit is defined as a regular, repeating path that one object in space takes around another one. An object in an orbit is called a satellite. A satellite can be natural like the earth or the moon. A satellite can also be man-made, like the International Space Station. The Arctic region is understood as encompassing the Arctic Circle and Iceland's northern maritime zones. ${ }^{16}$ The term cosmolegal merges cosmology, a branch of astronomy that involves the scientific study of the large-scale properties of the universe as a whole, with law, due to the need for a different understanding of the Earth and human-centric, global, politico-juridical space. It allows for a shift in the imagination and understanding of the cosmos, which would not see the human and its laws as a central actor of the Earth system and beyond, or as the apex owner and manager of its environment. The human is only one of the actors of the cosmos, known and unknown.

This Article will be divided as follows. The first section focuses on the $\mathrm{CH}_{4}$ craters in the Arctic and orbital debris in the context of lex lata. It demonstrates insufficiencies in the current regimes as they struggle to address the volumetric nature of greenhouse gases. The second section outlines the cosmolegal proposal. There is no assumption here that would suggest that rocks, $\mathrm{CH}_{4}$, or orbital debris have intentions. Rather, their agency is in the manner in which they can affect other entities. The hubris of the current dominant conceptualization of law lies in its determinism that humanity has an endless capacity to adapt and thrive through scientific and technological inventions, even in the context of environmental degradation in the Earth system and its orbital neighborhood. However, in extreme spaces, which are not inherently friendly to human life, the outcome is not determined. This includes outer space, the deep seas, parts of the polar regions, and so on. For this reason, cosmolegality is meant to provide a non-foundational and very broad space for a rethinking of law and lawmaking that would account for this indeterminacy.

\footnotetext{
${ }^{13}$ See Frank Biermann, Earth system Governance: World Politics in the Anthropocene (2014); Louis J. Kotze \& Rakhyun E. Kim, Earth System Law: The Juridical Dimensions of Earth System Governance, 1 EARTH SYS. GOVERNANCE 1 (2019).

${ }^{14}$ In law, this approach has been applied by the Earth System Governance (ESG) approach. This network originated in 2008 as a core project of the former International Human Dimensions Program on Global Environmental Change (IHDP). See Louis J. Kotze, Earth System Law for the Anthropocene: Rethinking Environmental Law Alongside the Earth System Metaphor Transnational Legal Theory, 11 TRANSNAT'L Legal Theory 75 (2020).

${ }^{15}$ See Explore STEM Resources for Educators, NASA, www.nasa.gov/stem/foreducators (last visited March 5, 2020).

${ }^{16}$ See Rachael Lorna Johnstone, OfFshore Oil and Gas Development in the Arctic under International Law 7 (2014).
} 


\section{B. Methane Craters in the Arctic and Orbital Debris}

Capacities or agencies of the non-human are not meant to become a version of human subjectivity. They are meant to be understood as much as possible on their own terms. This means that human-made laws would need to recognize that phenomena such climate change or orbital debris are indeterminate yet relevant for human survival and global governance. The non-human world does not perceive the human as the human perceives itself (as well as the limits of perception among humans). The Earth system includes human influences and is influenced by it, or is indifferent to the needs of human survival. Human are able to access the outer space or the deep seas with human-made technologies and, sometimes, with unpredictable consequences.

Despite its implications for all lawmaking, the cosmolegal proposal focuses on international law because climate change and orbital debris pose global challenges. Climate change and technological developments have contributed to the changing human interests in the non-human-dominated and still not fully understood realm of outer space: Extraterrestrial environment is now an opportunity for further commercial expansion such as the proposed space tourism or asteroid mining ${ }^{17}$ and even the search for the planet B solution. ${ }^{18}$ In addition, the fluidity and extraterritoriality of aggregate states beyond matter solidity ${ }^{19}$ have been a challenge for jus publicum terrae since the question of what law could the law among nations apply to the air or the "free seas." ${ }^{20}$ As scholarship on the history of international law has demonstrated, sixteenth and seventeenth century authors were charting out a law that would secure the right of free commerce, as they also created foundations for the law among nations. ${ }^{21}$ They did so, however, by applying the Christian theological notion of imago Dei, which sees the human as created in the image of God and, as such, different from other animals. $^{22}$ These origins stand at the core of modern international legal architecture.

The shadow of the state-centric nature of international law looms over instruments meant for the seas and outer space: The UN Convention on the Law of the Sea (UNCLOS) ${ }^{23}$ and Outer Space Treaty (OST). Both regulate certain anthropocentric collective utility and moral decisions, which

\footnotetext{
${ }^{17}$ Isabel Feichtner, Mining for Humanity in the Deep Sea and Outer Space: The Role of Small States in the Extraterritorial Expansion of Extraction, 32 LEIDEN J. INT'L L. 255 (2019) (arguing that the current structure of international legal framework allows extraterritorial landgrabs by granting states extraterritorial exploitation rights—or "the turning of the deep seabed and outer space into realms of commercial exploitation.”). See also THE HAGUE INT'L SPACE RES. GOVERNANCE WORKING GRP., Draft Building Blocks For the Development of an InTERnational Framework in Space Resource Activities (Nov. 12, 2019), https://www.universiteitleiden.nl/binaries/content/assets/rechtsgeleerdheid/instituut-voor-publiekrecht/lucht-enruimterecht/space-resources/bb-thissrwg-cover.pdf.

${ }^{18}$ Elon Musk, Making Humans a Multi-Planetary Species, 5 New SpaCE 46 (2017).

${ }^{19}$ In their seminal text, Philip Steinberg and Kimberley Peters have proposed that the ocean represents an ideal spatial environment to challenge the assumed fixity and groundedness of space. The "voluminous, stubbornly material, and unmistakably undergoing continual reformation of oceans," they write, is able to "reinvigorate, redirect, and reshape debates that are all too often restricted by terrestrial limits.” Philip Steinberg \& Kimberley Peters, Wet Ontologies, Fluid Spaces, 33 Soc’y \& SPACE 247 (2015).

${ }^{20}$ See Hugo Grotius, Commentary on the Law of Prize and Booty (M.J. Van Ittersum ed., 2006); Ileana Porras, Appropriating Nature: Commerce, Property, and the Commodification of Nature in the Law of Nations, 27 LEIDEN J. INT'L L. 641 (2014); Will Steffen, Paul J. Crutzen \& John R. McNeill, The Anthropocene: Are Humans Now Overwhelming the Great Forces of Nature?, 36 AmBIO 614, 617 (2007).

${ }^{21}$ Martti Koskenniemi, International Law and the Emergence of Mercantile Capitalism: From Grotius to Smith, in THE Roots of International Law / Les Fondements du droit international: Liber Amicorum Peter Haggenmacher 3 (Pierre-Marie Dupuy \& Vincent Chetail eds., 2013).

${ }^{22}$ Janne Nijman, Grotius' Imago Dei Anthropology: Grounding Ius Naturae et Gentium, in INTERNATIONAL LAW AND RELIGION (Martti Koskenniemi et al. eds., 2017).

${ }^{23}$ On UNCLOS, see Ori Sharon, Tides of Climate Change: Protecting the Natural Wealth Rights of Disappearing States, 60 HARV. INT'L L.J. 99 (2019), which demonstrates that "UNCLOS is an instrument for apportioning maritime rights between sovereign political entities, not divesting rights in catastrophes." Importantly, on the protection of marine life, see Pierre Cloutier de Repentigny, To the Anthropocene and Beyond: The Responsibility of Law in Decimating and Protecting Marine Life, 11 TrANSNAT'L LEgAL THEORY 180 (1964), which analyzes “the constitutive impact of economic profit and territoriality on the law of the sea."
} 
are also, more precisely, state- and commerce-centric. The Arctic and outer space are subject to the ongoing state and extractive industry sector-promoted rush for resources in newly accessible spaces. International regimes that govern both domains do not adequately reflect or respond to the magnitude of environmental degradation. ${ }^{24}$

\section{Climate Change in the Arctic}

The Arctic region is warming two times faster than the rest of the globe, and this may influence natural sources of GHGs, most of them being temperature dependent. One of the hypotheses is that the large craters embedded within $\mathrm{CH}_{4}$ leaking subglacial sediments in the Barents Sea and Siberia were likely widespread across past glaciated petroleum zones. They also provide an analogue for the potential future destabilization of sub-glacial gas hydrate reservoirs beneath contemporary ice sheets. ${ }^{25}$ If $\mathrm{CH}_{4}$ is allowed to leak into the air before being used, it rapidly absorbs the sun's heat, warming the atmosphere and contributing to the positive feedback loop of climate change in the Arctic and the rest of the Earth system. ${ }^{26}$

In the Arctic, $\mathrm{CH}_{4}$ is the major component of natural gas and is anthropogenically released into the atmosphere from a variety of sources and activities including coal mining, leaking natural gas pipelines, ruminant livestock such as cows, rice paddies, and solid waste facilities. ${ }^{27} \mathrm{CH}_{4}$ emissions in these industries could be the result of leaks from compressors, pumps, and pipelines, or vented from oil and gas wells and petroleum storage tanks. ${ }^{28}$ Like $\mathrm{CO}_{2}$, complex metabolic heat production and $\mathrm{CH}_{4}$ emissions need to be translated into the language of the law. Annex A to the Kyoto Protocol lists the six different greenhouse gases covered by the Protocol: Carbon dioxide $\left(\mathrm{CO}_{2}\right)$; methane $\left(\mathrm{CH}_{4}\right)$; nitrous oxide $\left(\mathrm{N}_{2} \mathrm{O}\right)$; hydrofluorocarbons (HFCs); perfluorocarbons (PFCs); and sulphur hexafluoride $\left(\mathrm{SF}_{6}\right){ }^{29}$ Different greenhouse gasses all have their own properties, characteristics, and lifetimes or periods of potency. In accordance with the Kyoto Protocol, they are represented in standardized terms of one ton of carbon dioxide equivalent $\left(1 \mathrm{tCO}_{2} \mathrm{e}\right) .1 \mathrm{tCO}_{2} \mathrm{e}$ is already "standardisable, exchangeable and commodifiable and ultimately tradable" under international law. ${ }^{30}$ This method of measurement has led to the well-documented problem of carbon leakage, which refers to the situation that may occur if, for reasons of costs related to climate policies, businesses were to transfer production to other countries with laxer emission constraints. $\mathrm{CO}_{2}$ pricing and trading could lead to an increase in total emissions. ${ }^{31}$ The carbon pricing instruments such as ETSs, carbon taxes, offsets, and hybrid instruments, such as variations of results-based climate finance, have been identified as essential in leveraging these financial transfers and enabling cooperation to mitigate climate change. ${ }^{32}$

\footnotetext{
${ }^{24}$ For the global commons perspective, see Isabel Feichtner \& Surabhi Ranganathan, International Law and Economic Exploitation in the Global Commons: Introduction, 30 EUR. J. INT'L L. 541 (2019) ("Yet current initiatives that seek to harness the economic potential of the oceans in the name of blue growth, projects seeking to commercialize outer space and, a fortiori, proposals to 'colonize' outer space and the oceans as a solution to conflict and environmental destruction stand in stark contrast with visions of a commons economy built on solidarity.").

${ }^{25}$ See Yumashev et al., supra note 1.

${ }^{26}$ Joeri Rogelj et al., Mitigation Pathways Compatible With $1.5^{\circ} \mathrm{C}$ in the Context of Sustainable Development, in Intergovernmental Panel on Climate Change, supra note 6.

${ }^{27} I d$.

${ }^{28} I d$.

${ }^{29}$ Kyoto Protocol to the United Nations Framework Convention on Climate Change, Dec. 11, 1997, 37 I.L.M. 22 [hereinafter Kyoto Protocol].

${ }^{30}$ Julia Dehm, One Tonne of Carbon Dioxide Equivalent (1tCO2e), in InTERnational LaW's ObJects (Jessie Hohmann \& Daniel Joyce eds., 2018).

${ }^{31}$ On the problems and limitations of the current $1 \mathrm{tCO}_{2} \mathrm{e}$ trading system, see generally Michael A. Mehling, Harro van Asselt, Kasturi Das, Susanne Droege \& Cleo Verkuijl, Designing Border Carbon Adjustments for Enhanced Climate Action, 113 AM. J. INT'L L. 433 (2019).

${ }^{32} I d$.
} 
The central aim of current climate governance ${ }^{33}$ has been to strengthen the global response to the threat of climate change, increase the ability of countries to deal with the impacts of climate change, and to make finance flows consistent with a low greenhouse gas emissions and climateresilient pathway. Part of this strategy has been to establish international carbon markets as a dominant climate mitigation strategy. ${ }^{34}$ To reach these goals, appropriate mobilization and provision of financial resources, a new technology framework, and enhanced capacity-building are to be put in place, thus supporting action by developing countries and the most vulnerable countries in line with their own national objectives. As climate governance coexists within the rest of the international law's multiple and overlapping regimes ${ }^{35}$ - that is to say, a space fragmentation and many norm-producing sites, which often function in parallel, conflicting, or overlapping waysthe globality of its aims is continuously mitigated by those plural interests.

The regimes governing the $\operatorname{Arctic}^{36}$ remain fragmented and complicit in the facilitation of interests of individual state-commercial-territorial nexus. ${ }^{37}$ This includes asymmetries that are deeply rooted in the historical, philosophical, political origins of the "law among nations." As such, these asymmetries require more than just a reordering of governance structures, but an "ontological turn" in how humans self-position in the Earth system. ${ }^{38}$ This, as is here argued, becomes even more evident if we understand the planetary implications of human activity.

\section{The UNCLOS Regime in the Arctic}

In the case of the Arctic, in the Ilulissat Declaration, ${ }^{39}$ the coastal states of the Arctic Ocean have codified the legal regime in the Arctic on the basis of the law of the sea rather than UNCLOS specifically, because the United States is not a party. However, as most of the law of the sea is codified in UNCLOS, it is significant as it forms the core framework of Arctic governance; especially significant is the question of Exclusive Economic Zones (EEZs). With deglaciation, approximately forty percent of the Arctic high seas is now open during the summer months, presenting commercial and industrial opportunities. It also alters the dynamics of the Earth system altogether, including ocean currents and ocean salinity. The area is defined in Article 1(1) of UNCLOS as "the seabed and ocean floor and subsoil thereof, beyond the limits of national jurisdiction." Global warming has immediate consequences for the ongoing debates regarding, among others, regime fragmentation and interactions, and it also can serve as a test for the possibilities of future forms of supranational governance, transnational governance, and treaty making. ${ }^{40}$ The Arctic high seas are the 2.8 million square kilometers that lie beyond the combined EEZ of the coastal states of the Arctic. The legal distinction between state jurisdiction and the area does not correspond to the current blurring of the lines which determine what we define as territory, or the EEZ, as determined by novel geological and other changes in the Earth system.

The structure of the Arctic governance is influenced by the combination of the UNCLOS framework of treaties, institutions, and implementing agreements as well as by the interests of

\footnotetext{
${ }^{33}$ See United Nations Framework Convention on Climate Change (UNFCCC), May 9, 1992, 1771 U.N.T.S. 107;Paris Agreement to the United Nations Framework Convention on Climate Change, Dec. 12, 2015, T.I.A.S. No. 16-1104.

${ }^{34}$ Dehm, supra note 30 .

${ }^{35}$ See generally Int'l Law Comm'n, Fragmentation of International Law: Difficulties Arising from the Diversification and Expansion of International Law, U.N. Doc. A/CN.4/L.702 (2006); Thomas Gehring \& Sebastian Oberthür, Institutional Interaction: Ten Years of Scholarly Development, in MANAGING INSTITUTIONAL COMPLEXITY: REgIME INTERPLAY AND Global Environmental Change 25 (Sebastian Oberthür \& Olav Schram Stokke eds., 2011).

${ }^{36}$ See discussion infra Section B(I)(1).

${ }^{37}$ See Isabel Feichtner, Contractor Liability for Environmental Damage Resulting from Deep Seabed Mining Activities in the Area, 114 MARINe Pol'y 1 (2019) (discussing the "mining code" proposals for deep-seabed mining).

${ }^{38}$ See generally Anna Grear, Towards a New Horizon: In Search of a Renewing Socio-Juridical Imaginary, 3 OÑATI SOCIOLEGAL SERIES 966 (2013).

${ }^{39} \mathrm{Id}$.

${ }^{40}$ Feichtner \& Ranganathan, supra note 24, at 541.
} 
sovereign nation-states. UNCLOS "lays down a comprehensive regime of law and order in the world's oceans and seas[,] establishing rules governing all uses of the oceans and their resources." 41 The treaty was modified in 1994 by an agreement relating to the implementation of Part XI of the treaty, which relates to the seabed and ocean floor and subsoil that are beyond the limits of national jurisdiction.

The UNCLOS grants the Arctic state on whose continental shelf they are located the exclusive rights to exploit any resources potentially existing there. ${ }^{42}$ As most of the Arctic is under the jurisdiction of one of the Arctic states, the international legal response to climate change as well as the extraction of resources in the Arctic has been mostly connected to individual state interests: Potential "grabs in the Arctic," questions of territorial sovereignty, access to the deep extractive industries, and other forms of natural resource exploitation. ${ }^{43}$ An extended continental shelf could mean access to profitable resources in the near future. ${ }^{44}$ Climate change has particular implications for UNCLOS provisions reliant upon water depth, contained in Article 76(5) on continental shelf delimitation. The potential sea-level rise also influences the definition of land under Article 121(3). Article 7(2) has a special rule designed for such conditions: "Where because of the presence of a delta and other natural conditions the coastline is highly unstable . . notwithstanding subsequent regression of the low water line, the straight baselines shall remain established." This provision emphasizes legal certainty over geological and geophysical changes. The task of regulating GHG emissions is outside the scope of UNCLOS, which can only address the effects of climate change and not its root cause in terms of the source of GHG emissions.

Under UNCLOS, extractive activities in the area are to be carried out in such a manner as to foster healthy development of the world economy and balanced growth of international trade, and to promote international cooperation for the overall development of all countries, especially developing states, per Article 150. If a corporation extracts the resources, the title to the resources shall pass upon recovery in accordance with UNCLOS Annex III, Article 1. Annex III of the Implementation Agreement of 1994 was added in response to the lack of support by a number of industrialized states for the 1982 outcome of UNCLOS negotiations. ${ }^{45}$ In the Preamble, it refers to "the political and economic changes, including market-oriented approaches, affecting the implementation of Part XI" and its overall purpose to "facilitate universal participation in the Convention." 46 The Agreement emphasizes the role of individual states and the globalized values of market economics.

\footnotetext{
${ }^{41}$ Convention on the Law of the Sea, Dec. 10, 1982, 1833 U.N.T.S. 397 [hereinafter UNCLOS]. It builds on the four treaties that resulted from the first Conference on the Law of the Sea, UNCLOS I, which took place in 1958. These are the Convention on the Territorial Sea and Contiguous Zone, which entered into force on September 10, 1964; the Convention on the Continental Shelf, which entered into force on June 10, 1964; the Convention on the High Seas, which entered into force on September 30, 1962; and the Convention on Fishing and Conservation of Living Resources of the High Seas, which entered into force on March 20, 1966. For additional discussion, see United Nations Conference on the Law of the Sea, DiPLOMATIC CONFERENCES, http://legal.un.org/diplomaticconferences/1958_los/ (last visited Feb. 3, 2021); Tullio Treves, 1958 Geneva Conventions on the Law of the Sea, AUdiOvisual LiBRARY OF INTERNATIONAL LAw, http://legal.un.org/avl/ha/gclos/gclos. html (last visited Feb. 3, 2021).

${ }^{42}$ See UNCLOS at Annex III, art. 3. 1. "The Enterprise, States Parties, and the other entities referred to in article 153, paragraph 2(b), may apply to the Authority for approval of plans of work for activities in the Area. 2. The Enterprise may apply with respect to any part of the Area, but applications by others with respect to reserved areas are subject to the additional requirements of article 9 of this Annex ...." After approval by the Council, the Secretary General issues the plan of work in form of a contract (Art. 153:3 UNCLOS). For a detailed discussion, and in comparison to outer space mining, see Feichtner, supra note 17 , at 258-260.

${ }^{43}$ Stephanie Holmes, Breaking the Ice: Emerging Legal Issues in Arctic Sovereignty, 9 CHI. J. INT'L L. 323,324 (2008).

${ }^{44}$ See Joanna Mossop, The Continental Shelf Beyond 200 Nautical Miles: Rights and Responsibilities (2016).

${ }^{45}$ See id.

${ }^{46}$ Agreement Relating to the Implementation of Part XI of the United Nations Convention on the Law of the Sea of 10 December 1982, U.N. Doc. A/RES.48.2663; ATS 32/33; ILM 1309 (June 3, 1994). The preamble of the 1994 Agreement reads in the original as: "Noting the political and economic changes including market-oriented approaches, affecting the
} 
Different regimes that overlap in the Arctic include the deep seabed mining law as laid down in Part XI on the area, Part XII on Protection and Preservation of the Marine Environment of UNCLOS, the relevant Annexes, the 1994 Implementation Agreement, and secondary law adopted by the ISA. They function in the context of other norms of international law that may complement the norms on responsibility and eventually subject deep seabed miners to strict liability obligations. For instance, UNCLOS Article 304 states that the provisions "regarding responsibility and liability for damage are without prejudice to the application of existing rules and the development of further rules regarding responsibility and liability under international law."

The UNCLOS regime does not provide for strict liability, but responsibility for wrongful conduct. Other international legal instruments that do provide for liability in the sense of liability for damage resulting from hazardous activities include the Outer Space Treaty (OST), ${ }^{47}$ the Convention on International Liability for Damage Caused by Space Objects, the Convention on the Regulation of Antarctic Mineral Resource Activities (CRAMRA), which never entered into force, or the Convention on Civil Liability for Oil Pollution Damage. For example, CRAMRA or the OST did not seek to promote commercial mining activities. ${ }^{48}$ Instead, these regimes prioritized ecosystem protection, prohibited mining in the absence of adequate information, and provided for strict liability of operators. ${ }^{49}$ Notwithstanding this approach, as the following section shows, it is these gaps present in the OST regime that have allowed for individual state legislation that promotes outer space mining without clear provisions for environmental protection.

The process initiated by the UN General Assembly (UNGA) Resolution 69/292 to develop the elements of an internationally legally binding instrument (ILBI) for conservation and sustainable use of marine biodiversity in areas beyond national jurisdiction has contributed to a discussion regarding a more integrated and cross-sectoral system of oceans governance at a global and regional scale. ${ }^{50}$ Centering only on areas beyond national jurisdiction does not take into account the fluid nature of the effects of climate change on the seas, ice, and the atmosphere. It is not clear how the sectoral- and boundary-defined approach would coordinate with broader climate change concerns and consequences.

The Arctic Council itself has called for the use of what it refers to as Ecosystems-Based Management (EBM). The EBM system articulated nine constituent principles, some of which recognize, inter alia, "that ecosystems and human activities are dynamic, that the Arctic is undergoing rapid changes, and that our understanding of these systems is constantly evolving, successful EBM efforts are flexible and adaptive." ${ }^{51}$ The EBM recognizes the need to reconcile a plurality of interests in the region. There is no single responsible institution whereby assessments would be coordinated in a central way, nor do the scientific understandings of the approaches to use converge. Indeed, this is necessary due to the expertise-based diversity of all the involved sectors. The EBM approach emerges from concerns over the protection of endangered species. ${ }^{52}$ It can recognize the position of a particular species in the ecosystem context, which includes humans. However, as

implementation of Part XI." One of the functions of the Authority is "to approve ... applications for mining contracts or licenses submitted to in the form of plans of work for exploration or exploitation.” Id. at $\$ 3$, para. 11(a) (emphasis added).

${ }^{47}$ Treaty on Principles Governing the Activities of States in the Exploration and Use of Outer Space, Including the Moon and Other Celestial Bodies, Jan. 27, 1967, 610 U.N.T.S. 205 [hereinafter Outer Space Treaty].

${ }^{48}$ See Feichtner, supra note 37, at 1 (discussing the "mining code" proposals for deep-seabed mining and clarifying "that the UN Convention on the Law of the Sea (LOSC) provides not for strict liability, but responsibility for wrongful conduct and that the international law of deep seabed mining does not include a no-harm rule").

${ }^{49} I d$.

${ }^{50}$ See generally Timo Koivurova \& Richard Caddell, Managing Biodiversity Beyond National Jurisdiction in the Changing Arctic, 112 Am. J. INT'L L. UnBound 134 (2018).

${ }^{51}$ Arctic Council, Ecosystem Based Management In the ARCTiC 13 (May 2013), https://oaarchive.arctic-council.org/ bitstream/handle/11374/122/MM08_EBM_report\%20\%281\%29.pdf?sequence=1\&isAllowed=y.

${ }^{52} I d$. 
discussed in the previous sections, the $\mathrm{CH}_{4}$ release into the atmosphere requires a step beyond the environmental protection approaches and also needs to recognize the not easily controlled "unintended consequences" of climate change. The latter is much more global in scale than the proposed EBM approach.

Instruments such as the UNCLOS and OST confer on states the role to ensure the compliance of private actors in relation to potential environmental harm resulting from resource extraction. However, the current authorization of extractive activities under UNCLOS or the increasing promotion of outer space activities under the OST have also widened the gap that allows for further "resource rush" for private industries and beyond national jurisdiction. This brief and non-exclusive discussion of legal regimes applicable in the Arctic demonstrates the ongoing limitations posed by the inherent state-centric and human-centric approach to global governance. The language of various instruments may reorient the focus of regulation and governance on conservation and protection. However, these have emerged without a coordinated effort to position the Arctic within the all-encompassing problem of global warming. Nor is there an attempt to fundamentally challenge the global political paradigm that is, in fact, internally self-limiting in any serious attempts to address global warming. Namely, the anthropocentric and state-centric foundation of international law has not allowed for the recognition of the full impact of climate change on the Earth system as a whole, or now more visible challenges of orbital debris.

\section{Orbital Debris ${ }^{53}$}

There are two ongoing issues in outer space governance that have intensified with advancements in technology and increased human access: Orbital debris in the low Earth orbit (LEO) and the governing of resource extraction in outer space. First, the current liability for damage resulting from hazardous activities does not specifically address private actors, as all activities in outer space are "national activities." Second, the private extension of human activity into outer space requires more monitoring because the existing international instruments focus on state-level responsibility.

The Committee on the Peaceful Uses of Outer Space (COPUOS) has been the forum for the development of international space law. It has concluded five international treaties and five sets of principles on space-related activities. ${ }^{54}$ These five treaties deal with issues such as the non-appropriation of outer space by any one country, arms control, the freedom of exploration, liability for damage caused by space objects, the safety and rescue of spacecraft and astronauts, the prevention of harmful interference with space activities and the environment, the notification and registration of space activities, scientific investigation and the exploitation of natural resources in outer space, and the settlement of disputes. Each of the treaties stresses the notion that outer space, the activities carried out in outer space, and whatever benefits might be accrued from outer space should be devoted to enhancing the well-being of all countries and humankind, with an emphasis on promoting international cooperation.

\footnotetext{
${ }^{53}$ This subsection primarily narrows on the current instruments that are relevant for space debris mitigation in the context of the growing state and private commercial interests in outer space.

${ }^{54}$ They are: The "Outer Space Treaty," or the Treaty on Principles Governing the Activities of States in the Exploration and Use of Outer Space, Including the Moon and Other Celestial Bodies, adopted by the General Assembly in its resolution 2222 (XXI), opened for signature on January 26, 1967 and entered into force on October 10, 1967; the "Rescue Agreement," or Agreement on the Rescue of Astronauts, the Return of Astronauts and the Return of Objects Launched into Outer Space adopted by the General Assembly in its resolution 2345 (XXII), opened for signature on April 22, 1968, and entered into force on December 3, 1968; the "Liability Convention," or the Convention on International Liability for Damage Caused by Space Objects adopted by the General Assembly in its resolution 2777 (XXVI), opened for signature on March 29, 1972, and entered into force on September 1, 1972; the "Registration Convention," or the Convention on Registration of Objects Launched into Outer Space, adopted by the General Assembly in its resolution 3235 (XXIX), opened for signature on January 14, 1975, and entered into force on September 15, 1976; and the "Moon Agreement," or the Agreement Governing the Activities of States on the Moon and Other Celestial Bodies, adopted by the General Assembly in its resolution 34/68, opened for signature on December 18, 1979, and entered into force on July 11, 1984.
} 
Environmental impact of activities in space unfolds on multiple scales: Local and stratospheric emissions from space launches, the placement of outer space related infrastructure in so called peripheral places, and the role of power in determining whether the use of such infrastructure aids socio-environmentally constructive or destructive practices.

To understand how serious the problem of space debris is, we need to first understand that LEO acts like highways for resident space objects. In other words, LEO contains limited lanes where satellites most naturally fall into orbit. As objects are continually launched into space, things are beginning to interfere with these paths, putting working satellites in danger. ${ }^{55}$ These satellites are used for critical services such as telecommunications and national security, but we also rely on them to gather information for important decision-making about agriculture, meteorology, climatology, and more. It is also important to recognize that most things put into space never come back or remain in orbit for well beyond our lifetimes. The population of space debris is self-growing as more things collide and break into even smaller pieces.

The orbital debris problem is further complicated by commercial interests of state and non state actors in asteroid mining and commercial uses of outer space, which focus on the new delineation, ownership, privatization, and extraction of space resources. Echoing a French law from the beginning of the eighteenth century, Article I of the Luxembourg Draft Law on the Exploration and Use of Space Resources argues that " $[\mathrm{t}]$ here is an even closer analogy in legal terms between space and the sea." ${ }^{56}$ According to the adopted law of July 13, 2017 that entered into force on August 1, 2017, Luxembourg's main objective is to provide "legal certainty as to the ownership of minerals and other valuable space resources identified in particular on asteroids." The adopted law argues that OST only prohibits the ownership of celestial bodies, but not the potentially extracted resources. It separates the definition of a celestial body from any resources to be found on that body.

Orbital regions represent valuable resources because they have characteristics that enable spacecraft operating within them to execute their missions more effectively. Functional spacecraft share the near-Earth environment with natural meteoroids and the orbital debris that has been generated by past space activities. Meteoroids orbit the Sun and rapidly pass through and leave the near-Earth region, or burn up in the Earth's atmosphere, resulting in a fairly continual flux of meteoroids on spacecraft in Earth's orbit. In contrast, artificial debris objects, including non-functional spacecraft, spent rocket bodies, mission-related objects, the products of spacecraft surface deterioration, and fragments from spacecraft and rocket body breakups, orbit the Earth and will remain in orbit until atmospheric drag and other perturbing forces eventually cause their orbits to decay into the atmosphere. Because atmospheric drag decreases as altitude increases, large debris in orbits above about 600 kilometers can remain in orbit for a very long time.

The possible mechanisms to regulate active space debris removal, including the issues arising in the implementation of active debris removal mechanism in law and the necessity for international cooperation at all levels regarding space debris issue, have yet to be developed. Presently, there is no internationally-agreed legal definition of orbital debris. It is generally understood to include human-made objects, including their fragments and parts, which are in orbital space, re-entering the Earth's atmosphere, or reaching the Earth's surface, that are non-functional, with no reasonable expectation of being able to assume their intended functions, or any other functions for which they are, or can be authorized. ${ }^{57}$ This may include spent rocket stages and defunct satellites, as well

\footnotetext{
${ }^{55}$ Alexandra Witze, The Quest to Conquer Earth's Space Junk Problem, NATURE (Sept. 5, 2018), https://www.nature.com/ articles/d41586-018-06170-1/.

${ }^{56}$ Space Translation of the Draft Law on the Exploration and Use of Space Resources, Luxembourg (draft law) (November 11, 2016), https:/gouvernement.lu/dam-assets/fr/actualites/communiques/2016/11-novembre/11-presentationspaceresources/Draft-law-space_press.pdf.

${ }^{57}$ See, e.g., Comm. on the Peaceful Uses of Outer Space, Technical Rep. on Space Debris, g, U.N. Doc. A/AC.105/720 (1999) ("Space debris are all man-made objects, including their fragments and parts, whether their owners can be identified or not, in Earth orbit or re-entering the dense layers of the atmosphere that are non-functional with no reasonable expectation
} 
as fragments from their disintegration, such as pieces of shielding. In accordance with international space law, all the above are considered space objects and their component parts ${ }^{58}$. As the functional status of a space object does not as such affect the applicability of rules of international space law, orbital debris remains subject to the same rules, which apply to space objects.

Some spacefaring states have voluntarily implemented non-binding space debris mitigation measures into their national space laws and technical standards as mandatory requirements. ${ }^{59}$ For other states, such recommendatory instruments can serve as an indication of an expected standard of due regard. In implementing space debris mitigation measures on a voluntary basis, states are recommended to follow some of the existing non-binding guidelines and technical standards, which have been developed by international governmental and non-governmental organizations and other international forums. ${ }^{60}$ In 2007, the UN General Assembly endorsed the Space Debris Mitigation Guidelines of the UN COPUOS ${ }^{61}$ and agreed that these voluntary guidelines reflected the existing practices as developed by a number of national and international organizations. ${ }^{62}$

Article I, paragraph 2 of the OST ${ }^{63}$ provides that outer space, including the Moon and other celestial bodies, shall be free for exploration and use by all states. However, there can also be a situation where a space operation of State A carried out near an asteroid generates a multitude of space debris orbiting around such asteroid on different planes, thereby making it technically impossible for a scientific spacecraft of State B to complete its space mission by landing on this asteroid and collecting a probe. In this situation, State A's creation of space debris infringes the freedom of exploration and use, which can no longer be enjoyed with respect to the asteroid in question, neither by State B nor by any other state. Article VI of the OST ${ }^{64}$ stipulates that an

of their being able to assume or resume their intended functions or any other functions for which they are or can be authorized.”); G.A. Res. 62/217, Space Debris Mitigation Guidelines of United Nations Comm. on the Peaceful Uses of Outer Space, Background, 1 (Dec. 22, 2007) ("For the purpose of this document, space debris is defined as all man-made objects, including fragments and elements thereof, in Earth orbit or re-entering the atmosphere, that are non-functional."); INTER-AGENCY Space Debris Coordination Comm., IADC Space Debris Mitigation Guidelines $\$ 3.1$ (2007) ("Space debris are all man made objects including fragments and elements thereof, in Earth orbit or re-entering the atmosphere, that are non-functional."); InT'L Org. For StANDARdization, Introduction to StANDARD 24113: Space Systems-Space Debris Mitigation REQUIREMENTS 1 (2011 ("Space debris comprises all non-functional, man-made objects, including fragments and elements thereof, in Earth orbit or re-entering the Earth's atmosphere."); EUROPEAN CODE OF CONDUCT FOR SPACE DEBRIS Mitigation 13 (2004) (“Synonym: orbital debris; Synonym: debris. . .[a]ny man-made space object including fragments and elements thereof, in Earth orbit or re-entering the Earth's atmosphere, that is non-functional.”).

${ }^{58}$ United Nations Convention on International Liability for Damage Caused by Space Objects art I(d), Mar. 29, 1972,961 U.N.T.S. 187[hereinafter Liability Convention]; United Nations Convention on Registration of Objects Launched into Outer Space art. I(b), June 6, 1975, 28 U.S.T. 695, 1023 U.N.T.S. 15[hereinafter Registration Convention].

${ }^{59}$ See U.N. Comm. On the Peaceful Uses of Outer Space, Part 1: National Mechanisms, in Compendium of Space Debris Mitigation Standards Adopted by States and International Organizations, http://www.unoosa.org/oosa/ en/ourwork/topics/space-debris/compendium.html. See also ChIna Nat'L Indus. STANDARd, Requirements FOR SpaCE Debris Mitigation (2006); Nat'l Standard of the Russ. Fed’n, Space Technology Items: General Requirements for Mitigation of Near-Earth Space Debris Population (2018).

${ }^{60}$ Part 2: International Mechanisms, in U.N. Comm. On the Peaceful Uses of Outer Space, supra note 59.

${ }^{61}$ G.A. Res. $62 / 217$.

${ }^{62}$ See, e.g., Inter-Agency Space Debris Coordination Comm., IAdC Space Debris Mitigation Guidelines (2020), https://orbitaldebris.jsc.nasa.gov/library/iadc-space-debris-guidelines-revision-2.pdf.

${ }^{63} \mathrm{See}$ Outer Space Treaty at art. I ("Outer space, including the moon and other celestial bodies, shall be free for exploration and use by all States without discrimination of any kind, on a basis of equality and in accordance with international law, and there shall be free access to all areas of celestial bodies.").

${ }^{64} I d$. at art. VI ("States Parties to the Treaty shall bear international responsibility for national activities in outer space, including the moon and other celestial bodies, whether such activities are carried on by governmental agencies or by non-governmental entities, and for assuring that national activities are carried out in conformity with the provisions set forth in the present Treaty. The activities of non-governmental entities in outer space, including the moon and other celestial bodies, shall require authorization and continuing supervision by the appropriate State Party to the Treaty ....."). 
appropriate state shall bear international responsibility for national space activities involving a space object, which can be classified as space debris, and for assuring that such activities are carried out in conformity with the provisions set forth in the OST. The second sentence of Article IX of the OST states that studies of outer space shall be pursued, and the exploration of outer space shall be conducted, so as to avoid its harmful contamination, and that States shall adopt appropriate measures for this purpose. ${ }^{65}$ Article 7, paragraph 1 of the Moon Agreement contains a similar provision-it obliges state parties, in exploring and using the Moon, to take measures to prevent the disruption of the existing balance of its environment by its harmful contamination. ${ }^{66}$ Importantly, space debris has an impact on the fragility of the outer space environment ${ }^{67}$ and is qualified as contamination stricto sensu.

For instance, if a space operation of State A that strictly followed space debris mitigation guidelines and standards caused damage to an in-orbit space object of another state, proving State A's fault may prove to be a more difficult task in comparison with proving fault of State B, who failed to comply with any of such guidelines and standards when carried out its space operation, which caused damage to another state's space object. As there are no mandatory international guidelines or standards of conduct for states and international organizations with respect to the creation of space debris, none of them can be used to definitively assess fault for the purpose of establishing international liability under Article III of the Liability Convention or to establish a universal standard of due regard. The recovery and return of space objects, which in such circumstances are usually space debris, is a central focus of the Rescue Agreement. ${ }^{68}$ In addition, it obliges the launching authority to immediately take effective steps to eliminate the possible danger of harm, which is believed to be produced by its space object or its component parts of a hazardous or deleterious nature.

How does the lack of clear legal status of orbital debris compare to the current domestic legislation on the commercial uses of outer space? In 2015, the United States launched its Commercial Space Launch Competitiveness Act. Its purpose is " $[\mathrm{t}] \mathrm{o}$ facilitate a pro-growth environment by encouraging the private sector investment and creating more stable and predictable regulatory conditions." 68 According to $\$ 51303$ of Title IV of the Space Resource Exploitation and Utilization Act, U.S. citizens engaged in commercial space mining shall be entitled to the extracted resources "including to possess, own, transport, use, and sell the asteroid resource or space resource obtained in accordance with applicable law, including the international obligations of the United States." ${ }^{\prime 2}$ On July 13, 2017, Luxembourg's parliament adopted a law on the licensing of commercial space mining and invested in private space mining companies. The law entered into force on August 1, 2017. ${ }^{70}$ Luxembourg's main objective is to provide "legal certainty as

\footnotetext{
${ }^{65} \mathrm{Id}$. at art. XI ("In the exploration and use of outer space, including the moon and other celestial bodies, States Parties to the Treaty shall be guided by the principle of co-operation and mutual assistance and shall conduct all their activities in outer space, including the moon and other celestial bodies, with due regard to the corresponding interests of all other States Parties to the Treaty. .. "). Article XI emphasizes the avoidance of "harmful contamination and also adverse changes in the environment of the Earth resulting from the introduction of extraterrestrial matter . ..". Article XI further states that "[a] State Party to the Treaty which has reason to believe that an activity or experiment planned by another State Party in outer space, including the moon and other celestial bodies, would cause potentially harmful interference with activities in the peaceful exploration and use of outer space, including the moon and other celestial bodies, may request consultation concerning the activity or experiment.")

${ }^{66}$ Agreement Governing the Activities of States on the Moon and Other Celestial Bodies, art. 7, para. 1, Dec. 5, 1979, 1363 U.N.T.S. 3 [hereinafter Moon Agreement].

${ }^{67}$ G.A. Res. 62/217, pmbl.

${ }^{68}$ Agreement on the Rescue of Astronauts, the Return of Astronauts and the Return of Objects Launched into Outer Space, Apr. 22, 1968, 672 U.N.T.S. 119 [hereinafter Rescue Agreement].

${ }^{69}$ U.S. Commercial Space Launch Competitiveness Act, Pub. L. No. 114-90, 129 Stat. 704 (2015). See 51 U.S.C. \$51303.

${ }^{70}$ Loi du 20 juillet 2017 sur l'exploration et l'utilisation des ressources de l'espace. Journal Officiel du Grand-Duché de Luxembourg, Mémorial A, No 674 du 28 juillet 2017. (Aug. 22, 2017) The Luxembourg Chamber of Deputies adopted a law on the exploration of space and the use of space resources on July 13, 2017; the Grand Duke signed the law on July
} 
to the ownership of minerals and other valuable space resources identified in particular on asteroids." The adopted law argues that OST only prohibits the ownership of celestial bodies, not the potentially extracted resources. It thus separates the definition of a celestial body from any resources to be found on that body. Article 2 of the adopted law indicates that the approved operator has to act in conformity with conditions of its approval and Luxembourg's international obligations. In the legal context, which does not even specify the treatment of space debris, such initiatives allocate value to space as a commercial resource and not a fragile area with unpredictable reactions. The United Arab Emirate (UAE) Space Agency announced the UAE Space Law on February 24, 2020. ${ }^{71}$ The UAE National Space policy Section 5.2 .5 shall promote programs such as "Exploration, mining, extraction and utilization of resources in space."72 The context is clearly stated whereby UAE is advancing its national interests in outer space and in relation to considerable growth and change in the global space economy. ${ }^{73}$

The international community is at a crossroad and can either recognize the special nature of outer space as a domain that does not inherently "belong" to humans, or it can follow the current unilateral interpretations that approach it as a space to be appropriated and commercialized. The above-described domestic initiatives might result in emergent customary international law principles. Indeed, mining space resources such as asteroids could greatly expand humanity's knowledge about the origins of the solar system, the Earth, the abundance of water, and the origin of life. It could also provide knowledge about the composition and structure of asteroids. Being able to use satellites to connect space-weather phenomena with geophysical processes such as earthquakes would be a type of multidomain fusion that can have beneficial outcomes. It allows for an understanding of causal relationships among phenomena and the building of models that better predict how to address issues such as climate change. However, the model that applies marketbased approach to outer space, and in the context that lacks effective environmental controls, including space debris mitigation, is likely to translate earthly environmental problems into space. Considering that debris moves at a speed of 21,600 miles per hour, increased commercialization of outer space without environmental regulation and the impact of orbital pollution is uncertain, as is its impact on the Earth system or human life in outer space. In reference to the alternate image of multiple and divergent human and non-human worlds which come together in the matters of global warming or outer space exploration and the existing governance in practical terms, the law is not there yet.

20, 2017. (Loi du 20 juillet 2017 sur l'exploration et l'utilisation des ressources de l'espace [Law of July 20, 2017 on the Exploration and Use of Space Resources], Journal officiel du Grand-Duché de Luxembourg [Official Gazette of the Grand Duchy of Luxembourg], No. 674 (July 28, 2017), Lexilux; Draft Law on the Exploration and Use of Space Resources, spaceresources.lu (July 13, 2017).

${ }^{71}$ UAE Space Agency, UAE Space Agency Home Page, https://space.gov.ae/ (last visited Jan. 22, 2020).

${ }^{72}$ U.A.E. Space Agency, National Space Policy of the U.A.E. \$ 5.2.5, https://space.gov.ae/Documents/ PublicationPDFFiles/UAE_National_Space_Policy_English.pdf. Section 5.3.5 clearly argues for the commercialization for outer space: "5.3.5. Promote Creative Entrepreneurship and Commercial Space Projects: The UAE recognises that entrepreneurship catalyzes economic growth, increased employment, and innovation. The UAE Space Agency shall provide support to relevant government authorities, private sector entities and other relevant stakeholders to identify new commercial opportunities for market and technology growth."

${ }^{73}$ See the Introduction:

Outer space is getting busier, with more emerging technologies and an increasing number of countries and entities that seek to exploit the advantages of outer space, in the context of a wider contribution from the commercial and academic sectors and a higher level of cooperation between space-faring nations. In light of these developments, the planning and management of national capabilities and capacities requires clarity in the government's approach and goals with respect to the national space sector. For this reason, as the competent authority on this issue, and in accordance with Federal Law No.1/2014, the UAE Space Agency developed the National Space Policy. .." Id. at 15. 


\section{The Cosmolegal Proposal ${ }^{74}$}

Gases, objects, and the Earth system already have agency even if they are not recognized as such in the legal playing field. The state is reliant on the terrain as a motionless surface. However, in order to establish sovereignty over volume, for instance, it needs to create imaginary measurements such as "one tonne of carbon dioxide equivalent $\left(1 \mathrm{tCO}_{2} \mathrm{e}\right)$. ". Similarly, lines of an axis cannot represent an orbit round, which is a spacetime of orbital speed. The current state sovereignty on the one hand and global warming and orbital debris on the other hand are not coextensive, and therefore require non-cohesive regulation.

GHGs act in accordance with non-human biochemical and other laws, and as such, influence all life in the Earth system. Human-made orbital debris now needs to be controlled in a variety of ways, including, for instance, accurate prediction of the future path of debris in deciding if and when to maneuver satellites to avoid collisions. In these instances, the following questions could also be asked: How do we follow laws such as the geochemical or biological cycles of the Earth systems instead of the market-based greenhouse gas trading system? How can international law extend into orbital space, which is governed by a different spacetime? In trying to answer such questions, the cosmolegal proposal does not imply that gases would enter the courtroom. The cosmolegal challenges the appearance of distinctions and disparate attributes of the world. The Earth system as a whole demonstrates that its apparent fracturing in human understanding, practice, and regulation does not stem from its own inherent multiplicity, but from the human understanding thereof. The law, instead of being the mirror of permanently split human subjectivity, would recognize the indeterminate nature of the world beyond it.

The cosmolegal proposal builds on the hypothesis of profound interrelatedness in the Earth system. ${ }^{76}$ In addition, it seeks to adapt to international law certain components of the complex systems approaches. ${ }^{77}$ As the current legal fragmentation and conflict of laws demonstrates, analysis or regulation of each individual component has proven difficult in the regulation of the relationships among all components. International legal governance would need to be able to address emergent behaviors that are not always predictable. The current state sovereignty on the one hand and global warming and orbital debris on the other hand are not coextensive, and therefore require non-cohesive regulation.

Unlike the aims of complex systems theory to reveal all possible patterns, cosmolegality proposes a more flexible thinking towards the Earth system and cosmos. We cannot ignore ongoing developments in the human self-assertion in outer space, and therefore the "cosmos" aspect of "legality" is not improbable. Rather, these debates have been present for quite some time. ${ }^{78}$ In practice, there are existing efforts in civil society and academia to provide a commentary on the future of international lawmaking on the interrelatedness of outer space and the Earth system. Novel challenges are a constant issue for the legal discipline, including new discoveries, technological advances, environmental changes, and the like.

\footnotetext{
${ }^{74}$ This argument is only partly influenced by complex systems and the new ecology approaches, which have already proposed methodologies based on systems approaches. Systems require more than one perspective in order to account for potentially endless and interconnected possibilities and interactions. Moreover, as GHGs and orbital debris demonstrate, there are both simultaneous and contradictory patterns of activity in similarly complex and not yet fully understood spacetime.

${ }^{75}$ Dehm, supra note 30.

${ }^{76}$ See BIERMANN, supra note 13 ; Kotze \& Kim, supra note 13 , at 1.

${ }^{77} \mathrm{~A}$ study on the Earth system's hydrosphere and the use of the orbit for its observation demonstrates an interrelation of various subsystems in one complex system model that cannot be easily addressed by conventional law and policymaking. It interrelates the environment, social impact, human decision-making, and technology as just some of the domains with complex interactions. An integrated model seeks to weave all of these together into one complex systems model. See Elena Cirkovic, Space for Water in the Earth System: Space Technologies, Climate Change, and the Water Framework Directive (forthcoming, on file with author).

${ }^{78}$ See, e.g., Wilfred Jenks, Space LaW (1965).
} 
The hypothesis is that the arguments for law_as performing and enacting interventions as reasons in mental operations, incentives in utility calculations, and moral decisions - are still too anthropocentric. Cosmolegality requires a different ontological approach, ${ }^{79}$ as it recognizes the possibility of many co-present variables. The key working method of the cosmolegal project is to facilitate cooperation and interaction among different disciplines and knowledge, including an opening for contingencies provided by the agency of the non-human and other dimensions or spaces where humans seek to extend their activities and life. Part of the cosmolegal argument rests on the hypothesis that a claim to a total understanding of natural phenomena such as climate change, geoengineering, or orbital debris are not accurate. There is insufficient data to predict the long-term effects.

The proposed thinking seeks to delineate the law's disciplinary extension towards the inclusion of the Earth system as a planetary entity, and therefore, also in relation to extraterrestrial spacetime. In practice, it should be rich enough to capture a wide variety of learning problems. Cosmolegality would deploy two methodological toolsets: doctrinal and theoretical analysis of existing law. While these are standard methods in legal studies, they gain new undertones in this proposal as they become deployed in uncertain and prospective settings. As the law is either still developing or is not there at all, such research would have to parse together the future law applicable to non-human agencies from data, conceptual structures, and materials emanating from other contexts and disciplines. Certainly, doctrinal speculation is a misnomer and carries significant risks. This is why the future-oriented themes require strong interdisciplinary cooperation even if the learning curves would be steep. This would involve a transdisciplinary learning and gathering of information about the dynamics of the world. If the domain specification does not have to be complete, then the lawmaking process involves constant learning about how the world works. The sequence of the learning and lawmaking processes would be as follows: 1. Ontology; 2. Epistemology and Theory; 3. Policies and Law.

At the same time, there is no dimension-like quantity or criteria that can characterize learnability in some other form of totality. This will be a learning process, which will also use sequences of percepts to estimate the missing detail in world dynamics.

The general proposal of this Article is meant to be an unsettling of what seems to be knowable, while at the same time embodying a normative, and admittedly, finite and preconfigured objective that focuses on protection - or mitigation and prevention of further environmental degradationof the Earth system and outer space. What might be the use of such thinking? In order to answer this question, at least partially, transdisciplinary approaches are necessary.

The transdisciplinary aspect of the proposed cosmolegal principle and method does not automatically mean a borrowing or translation of other disciplines. Instead, it seeks to present possibilities rather than absolutes. For example, a combination of social sciences with natural sciences does not automatically provide correct answers. Philosophy of science has been grappling extensively with this tension between the social and scientific. ${ }^{80}$

For instance, the appropriation of quantum mechanics beyond physics has allowed for an understanding beyond ontologies of spheres or levels, challenging the nature-culture divide. It offers a thinking of possibilities famously represented in the double-slit experiment and its variations. ${ }^{81}$ Namely, because the experiment demonstrates that light and matter can unpredictably display characteristics of both classically defined waves and particles, it also showed the fundamental limitation of the ability of the observer to predict experimental results. In reference to the double-slit experiment, Richard Feynman stated, "[w]e choose to examine a phenomenon which is impossible, absolutely impossible, to explain in any classical way, and which has in it the heart of quantum mechanics.

\footnotetext{
${ }^{79}$ See Ian Burton \& O. Pauline Dube, Managing the Risks: International Level and Integration Across Scales, in MANAGING the Risks of Extreme Events and Disasters to Advance Climate Change Adaptation 393 (2012).

${ }^{80}$ Bruno Latour, Politics of Nature: How to Bring the Sciences into Democracy 75 (2004).

${ }^{81}$ The double-slit experiment is a demonstration in modern physics that light and matter can display characteristics of both, what are classically defined waves and particles. This possibility also demonstrates the probabilistic nature of quantum mechanics. See Richard Feynman, The Feynman Lectures on Physics 1.1-1.8 (1965).
} 
In reality, it contains the only mystery." 82 In other words, there are different possibilities, reactions not easily predictable by the human mind, and constantly changing limitations on what or whom is not knowable. The existence of the unknowable, then, could be seen as an invitation to reimagine the world. The following section looks at some of the current state of the art on the topic of the nonhuman and its agency and how it might find its way into international lawmaking.

The idealizing assumption of the world's total knowability and determinability in accordance with laws that humans perceive or create, in turn, leads to frustration with the limits imposed by them. Cosmolegality would need to be constantly open to contingencies in future coefficients of friction-observable friction among various processes, hence deviating from what might be considered as a normal relation. In the rest of this section, I will delineate some of the theoretical and methodological aspects of the proposal with the focus on non-human agency and indigenous peoples' traditional knowledges.

\section{Non-Human Agency}

The cases of GHGs and orbital debris bring to the fore a variety of issues posed by human-nonhuman interactions, including different dimensions and aggregate states. The cosmolegal proposal belongs to legal approaches, which emphasize the multidimensional and interactive nature of human reality. It echoes the posthuman approach of political theorist Jane Bennett, who has argued for the term "vibrant matter" in political agency of the non-human and defines "vitality" as the capacity of things such as metals to influence the will and designs of humans and to act as agents or forces with laws of their own. ${ }^{83}$ This perspective recognizes the capacity of anything non-sentient to influence its surroundings. In the case of $\mathrm{CH}_{4}$ craters, the overall process of global warming that causes them has been human initiated. However, GHGs act in accordance with non-human biochemical and other laws and as such influence all life in the Earth system. Human-made orbital debris now needs to be controlled in a variety of ways, including for instance accurate prediction of the future path of debris in deciding if and when to maneuver satellites to avoid collisions.

The volumetric movements of GHGs such as $\mathrm{CH}_{4}$, melting ice, and fluid spaces and the rapid orbital movement of space debris require a novel legal understanding of spaces beyond the Earthly surface and a more coherent volumetric framework for research and governance. For instance, Stuart Elden's 2013 article, Secure the Volume, argues for the necessity to rethink geography in terms of volumes rather than areas. ${ }^{84}$ This scholarship has been prominent especially among geographers. In more recent years, an increasing cohort of anthropologists have also been actively engaging with the volumetric, both in terms of new research and in revisiting past work.

The legal debates over the status of animals, corporations, unborn, non-biological machines, and nature have, for their part, made questions regarding what is the specific character enjoyed by natural persons, living human beings, that make their actions significant and their rights legally enforceable in comparison to these other entities, or the things. ${ }^{85}$ According to Latour, "[i]nstead of making the distinction between subjects and objects, we shall speak of associations between humans and non-humans." 86 The network of associations ${ }^{87}$ between humans and non-humans recognizes

\footnotetext{
${ }^{82} \mathrm{Id}$.

${ }^{83}$ Jane Bennett develops a theory of vital materialism that employs the Deleuzian notion of assemblages to conceptualize the diffuse set of actors, both human and not, that are involved in the enactment of any given phenomena. Her goal is "to articulate a vibrant materiality that runs alongside and inside humans to see how analyses of political events might change if we gave the force of things more due." Jane Bennett, Vibrant Matter: A Political Ecology of Things, at vii (2010).

${ }^{84}$ Stuart Elden, Secure the Volume: Vertical Geopolitics and the Depth of Power, Pol. Geography 34, 35 (2013).

${ }^{85}$ See Toni Selkälä \& Mikko Rajavuori, Traditions, Myths, and Utopias of Personhood: An Introduction, 18 GERMAN L.J. 1017 (2017); Mika Viljanen, A Cyborg Turn in Law?, 18 GERMAN L.J. 1277 (2017).

${ }^{86}$ LATOUR, supra note 80 , at $237-38$.

${ }^{87} I d$.
} 
non-human agency, or actancy. ${ }^{88}$ In contrast, international law has been designed to regulate human behavior. It is built on certain assumptions of how human beings behave and demonstrate agency.

Finally, while a biological or material mechanism does auto-develop according to a set of its own laws, these laws, as Earth system science demonstrates, are not based on fully self-enclosed systems. ${ }^{89}$ In addition, a biological life or matter does not need to be aware of itself to have agency..$^{90}$ Nor does this mean that the category of the subjective experience is superfluous, or unnecessary, to the materialism displayed by matter. It is important to account for the uncertainty of complex interconnectedness.

\section{Indigenous Peoples' Knowledge}

Transdisciplinary collaboration cannot promote new knowledge without the recognition and elimination of discrimination in existing sites of knowledge production. STS and other approaches have been discussing the role of science in maintaining and promoting existing dominant hierarchies. ${ }^{91}$ Cosmolegality hence also implies plurality, which would, among others, include traditional indigenous knowledges in decision-making.

Indigenous ontologies are presently mentioned in the semantics of the climate change regime or Arctic governance. ${ }^{92}$ Nonetheless, the inclusion or mention does not mean equal consideration in the practice of lawmaking. ${ }^{93}$ The actual experience in a number of jurisdictions demonstrates ongoing conflicts between indigenous and other interests. ${ }^{94}$ In its recommendations, IPCC has proposed a mobilization of "new, traditional and indigenous knowledge." ${ }^{\text {"Th }}$ There is still a lack of genuine collaboration and participation in how traditional indigenous knowledges are understood or approached. ${ }^{96}$ Furthermore, as indigenous societies are incredibly diverse, it is important not to make over-generalized assertions and judgments regarding who is indigenous or the specifics of indigenous knowledge. In particular, a substantial amount of indigenous knowledge is accessible through published academic words authored by indigenous scholars and is part of higher education curriculums. ${ }^{97}$ There is a difference in using indigenous knowledge as a framework of reference from a mere and

\footnotetext{
${ }^{88} I d$.

${ }^{89}$ See Steffen, Crutzen \& McNeill, supra note 20.

${ }^{90}$ Bruno Latour, Reassembling the Social: An Introduction to the Actor-Network Theory 71 (2005).

${ }^{91}$ See Elena Blanco \& Anna Grear, Personhood, Jurisdiction and Injustice: Law, Colonialities and the Global Order, $10 \mathrm{~J}$. HUM. RTS. AND THE ENV'T 86 (2019).

${ }^{92}$ See, e.g., Resolution of 16 March 2017 on an Integrated European Union Policy for the Arctic, Eur. PArL. Doc. 2016/ 2228(INI) (2017).

${ }^{93}$ Nagoya Protocol on Access to Genetic Resources and the Fair and Equitable Sharing of Benefits Arising from their Utilization to the Convention on Biological Diversity, Oct. 29, 2010, 3008 U.N.T.S. 1, arts. 5-7 [hereinafter Nagoya Protocol].

${ }^{94}$ U.N. Permanent Forum on Indigenous Issues, 18Th Session of the Permanent Forum (2019) Actionable RECOMMENDATIONS MATRIX (2019), https:/www.un.org/development/desa/indigenouspeoples/wp-content/uploads/sites/ 19/2019/09/6.-PFII-reccs-to-AFPs-2019-Session-annual-meeting-Geneva.pdf.

${ }^{95}$ The broad ways in which indigenous content is framed in IPCC mirrors other such portrayals of indigenous peoples, their knowledge, and experiences in general scientific and popular discourse, forming part of what Roosvall and Tegelberg term the "victim-heroes" frame. The complexity and diversity of experiences, understanding, and responses to climate change evident in the scholarship is not captured. See Anna Roosvall \& Matthew Tegelberg, Misframing the Messenger: Scales of Justice, Traditional Ecological Knowledge and Media Coverage of Indigenous Peoples and Climate Change, in MEDIA MEETs Climate: The Global Challenge for Journalism 297 (Elisabeth Eide \& Risto Kunelius eds., 2012).

${ }^{96}$ Indeed, some domestic initiatives have taken place in the form of a historically belated recognition and the inclusion of indigenous peoples' legal systems. The Te Awa Tupua (Whanganui River Claims Settlement) Act of 2017 in New Zealand, for instance, recognized rivers as legal persons. Article 14 of the Act declares the Te Awa Tupua river to be a legal person with all the corresponding rights, powers, duties, and liabilities, which in turn are exercised by Te Pou Tupua peoples on behalf of, and in the name of, Te Awa Tupua. In this manner, the rights of nature, as traditionally recognized in indigenous cosmovision, are also included in the dominant legal system, as represented by indigenous peoples. As such, the right of the river still requires the "stewards of nature" approach to indigenous peoples who have the particular position as its "protectors." Te Awa Tupua (Whanganui River Claims Settlement) Act 2017 (N.Z.), http://www.legislation.govt.nz/act/public/2017/0007/latest/whole.html.

${ }^{97}$ See, e.g., Glen Sean Coulthard, Red Skin, White Masks: Rejecting the Colonial Politics of Recognition (2014); Glen Coulthard \& Leanne Betasamosake Simpson, Grounded Normativity / Place-Based Solidarity, 68 AM. Q. 249 (2016).
} 


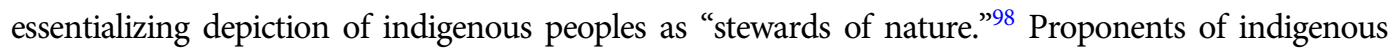
research paradigms do not deny the usefulness of Western methods, including the emphasis on empirical evidence. Instead, they call for us as researchers ${ }^{99}$ to place Western methods and paradigms into the context, which includes the colonial project and the valorization of those same ways of knowing.

In describing her own work, for instance, Leanne Simpson has argued, "I did not want to study Aboriginal people, or my culture, or even Traditional Ecological Knowledge, but I wanted to study the people who were writing about TEK, defining it and documenting it in the area of the environment, and I wanted to do this from the Anishinaabe perspective." 100 Simpson turns the research method upside down as she uses the Anishinaabe perspective to analyse nonAboriginal research on Aboriginal knowledge. Moreover, all research questions do not have to be community-generated. It is not a methodological necessity to engage in "fieldwork," depending on the disciplinary definition thereof, whereby Western scholars engage with or travel to indigenous communities, as multidisciplinary research in indigenous studies, is increasingly as accessible as any other knowledge. The inclusion of indigenous knowledge in the form of a proposal does not equate consideration in the practice of lawmaking. ${ }^{101}$

The cosmolegal project refers to indigenous scholarship in order to present what Karen Barad has described:

A multiplicity of paths and histories and the situatedness of time are also aspects of quantum temporality, which is not to suggest that (specific) quantum and (specific) indigenous approaches are identical or commensurate or have the same effect or stakes, but they do share in offering disruptions of the conception of homogenous empty time. ${ }^{102}$

What I mean by this is evident in the following example. Namely, Steinberg and Peters have questioned the materiality, motion, and temporality of the sea in order to "allow for new ways of thinking that are not possible when only thinking with the land." ${ }^{103}$ In so doing, they develop a term "wet ontology" - a way of thinking about the world that comes from a wet, watery perspective. ${ }^{104}$ Liquidity, however, is not a metaphor, but a process independent of human decision-making.

With relevance for "wet" thinking, the ontological elements raise a spatial dynamic to the arterial flows of water-as-lifeblood, which aboriginal elders of the Canadian Anishinabek nation have described as "blood veins of the Earth." ${ }^{105}$ Water as a flowing, living, and connected being sustains life, not just in our bodies, but also among the ecosystems from and through which healthy water must inevitably travel. ${ }^{106}$ An ontology such as water-as-lifeblood therefore raises awareness of the centrality of water as a living being, and of the relational connections that we all have with often distant life-sustaining waters. The cosmolegality here seeks to instead engage with ontologies that already recognize non-human agency as such, and in so doing, also

\footnotetext{
${ }^{98}$ Leanne Simpson, Aboriginal People and Knowledge: Decolonizing Our Processes, 21 CAN. J. Native StUd. 138 (2001).

${ }^{99}$ Robert Alen Warrior, Tribal Secrets: Recovering American Indian Intellectual Traditions (1995); Dennish McPherson \& J. Douglas Rabb, Some Thoughts on Articulating a Native Philosophy, 1 AyAangWAAmIzIN 3 (1997).

${ }^{100} I d$.

${ }^{101}$ In the case of the Convention on Biological Diversity (CBD), its implementation is supported by the Nagoya Protocol, which sets out a framework where fair and equitable compensation for local and indigenous producers of biological and genetic resources must be made conditional for access to these resources to be given. Nagoya Protocol at arts. 5-7.

${ }^{102}$ Karen Barad, Meeting the Universe Halfway: Quantum Physics and the Entanglement of Matter and MEANING (2007).

${ }^{103}$ Steinberg \& Peters, supra note 19 , at 247-64.

${ }^{104} \mathrm{Id}$.

${ }^{105}$ Kim Anderson, Barbara Clow \& Margaret Haworth-Brockman, Carriers of Water: Aboriginal Women's Experiences, Relationships, and Reflections, 60 J. CleAner Prod. 11 (2013).

${ }^{106}$ Katherine Cave, Exploring the Influences of Institutions on Water Governance and Management: First Nation Case Study (Jan. 20, 2012) (M.E.S. thesis, University of Waterloo), http://uwspace.uwaterloo.ca/bitstream/10012/6492/3/Cave_Katherine_ 2012.pdf.
} 
engages with issues of social and historical justice. Indigenous and other peoples often cast as "outside" of modernity have already long stressed multiple and relational ontologies, ${ }^{107}$ which remain under-unexplored in much of the current research on Earth system governance, or non-human entities. ${ }^{108}$ Part of the cosmolegal project, in practice, would require an awareness of these issues, suggesting that engaging substantially with the implications of a politics of multiple ontologies might provide a better understanding of conflicts that emerge when particular governance and management options are proposed and, at times, challenged. ${ }^{109}$ This sensitivity is especially needed in settler-colonial contexts where modern legal ontologies remain hegemonic.

There is an enormity in the question of how various peoples engage with the Earth system and outer space in their respective worldviews. The proposal of this Article is not meant to be comprehensive in that regard. Instead, it echoes the ongoing proposals in practice, among various communities, to keep the future of both Earth System and outer space governance as accessible to-and debatable by - all. This would include the human and non-human.

A particular theory or method cannot be easily applied everywhere. In other words, a theoretical model cannot predict the unknown, as we do not yet even know how to formulate the potential unknown in terms of the theory. Contingency is the essence of its proposal. It requires that humans imagine a model of the situation, which would lend itself to interpretation and without any guarantee that adequate models can be constructed for every possible situation. This entails an entirely new approach to law, which first has to recognize its limitations as rooted in the very foundations of the law, including international law, and then implement a diversity of methodologies depending on context and suitability.

\section{Conclusion}

By employing interdisciplinary literature, this Article has attempted to put into practice the cosmolegal proposal. Cosmolegality proposes that lawmaking will have to be very much like the domains where it is not possible to create a compact program. There is a practical need for further studies of the complex area of Earth system governance, the public and private access to outer space, and what these categories might even mean in a completely different spacetime.

The existing international legal instruments governing the Arctic high seas and outer space as commons are state-centric and, as such, contain within them provisions that would allow for the increasing promotion of state territorial and commercial interests even beyond national jurisdictions. Examples include the gap in the OST allowing for states to enact commercial laws for outer space mining, the expansion of the continental shelf under the UNCLOS regime, or the existing no-harm or liability provisions for the mining of the deep-seas. ${ }^{110}$ Also, most of the Arctic region is under state jurisdiction.

\footnotetext{
${ }^{107}$ Julian Yates, Leila M. Harris \& Nicole J. Wilson, Multiple Ontologies of Water: Politics, Conflict and Implications for Governance, 35 Env't \& Plan. D: SOC'y \& SPACE 797 (2017).

${ }^{108}$ As Leanne Simpson argued in 2001:

Non-Aboriginal researchers are flocking to Aboriginal communities. For Aboriginal peoples, at least initially, this was a good thing. After years of appropriating, assimilating, ignoring, undermining and degrading our knowledge, it was finally acknowledged by members of the dominant society. But outside researchers were not interested in all kinds of knowledge, and they remain specifically interested in knowledge that parallels the western scientific discipline of ecology or the environment, Aboriginal Peoples and Knowledge and they are often looking specifically for information that presents solutions to their own pending ecological crises.

Simpson, supra note 98 , at 138 .

${ }^{109}$ For examples of conflicts with the extractive industries, see generally DAVID SzABLOWSKI, TRANSNATIONAL LAW AND Local Struggles: Mining, Communities and the World Bank (2007); Gordon Christie, Indigeneity and Sovereignty in Canada's Far North: The Arctic and Inuit Sovereignty, 110 S. ATL. Q. 329 (2011); Elena Cirkovic, Community, Law, and Justice: Conflict Between Indigenous Peoples' Claims to Self-Determination and the Transnational Extractive Industry in Peru and Canada (2010) (Ph.D. dissertation, Osgoode Hall Law School, York University).

${ }^{110} I d$.
} 
The Earth system as a whole demonstrates that its apparent fracturing in human understanding, practice, and regulation does not stem from its own inherent multiplicity, but from the human understanding thereof. The same applies to outer space, or the cosmos. The cosmolegal proposal argues that law, instead of being the mirror of permanently split human subjectivity, could recognize the indeterminate nature of the world beyond it.

As Donna Haraway has argued, "[i]t matters which stories tell stories, which concepts think concepts. Mathematically, visually, and narratively, it matters which figures figure figures, which systems systemize systems." "It matters how the "stories tell stories" in the legal context, how humans define the spaces in which they live and operate, or which sciences and knowledges are consulted and referenced. What also connects the Earth system and outer space is the argument, or imagination, that in the case Earth becomes uninhabitable (and not only for that reason), humans can and will colonize other planets.

Indeed, there are too many ways the world could be, and there are too many sequences of precepts that one could have of the world. It is not possible to anticipate them all. The cosmolegal research horizon builds on this hypothesis of discontinuity. On the one hand, ongoing and constant changes are likely to contribute to new imaginations within the existing anthropocentric conceptual structures. On the other hand, we will need novel responses, adaptations, and legal modalities that can go beyond the human-centric model.

\footnotetext{
${ }^{111}$ Donna Haraway, Anthropocene, Capitalocene, Plantationocene, Chthulucene: Making Kin, 6 EnVTL. HUMAN. 159, 160 (2015).
}

Cite this article: Cirkovic E (2021). The Next Generation of International Law: Space, Ice, and the Cosmolegal Proposal. German Law Journal 22, 147-167. https://doi.org/10.1017/glj.2021.4 